\title{
A Cuckoo MPPT based SMC Control for Grid tied PV System
}

\author{
Meneni Saigeetha $^{1}$ | G Vaddikasulu ${ }^{2}$ \\ ${ }^{1}$ PG Student, Dept of EEE, Vikas Group of Institutions, Vijayawada, India \\ ${ }^{2}$ Assistant Professor, Dept of EEE, Vikas Group of Institutions, Vijayawada, India
}

\section{To Cite this Article}

Meneni Saigeetha and G Vaddikasulu, "A Cuckoo MPPT based SMC Control for Grid tied PV System", International Journal for Modern Trends in Science and Technology, 6(8): 22-26, 2020.

\section{Article Info}

Received on 02-June-2020, Revised on 26-June-2020, Accepted on 23-July-2020, Published on 28-July-2020.

\section{ABSTRACT}

Maximum power point techniques (MPPT) are used in photovoltaic system to make full utilization of PV array output power. The output power of PV array is always changing with weather conditions i.e., solar irradiation and atmospheric temperature. $P V$ cell generates power by converting sunlight into electricity. The electric power generated is proportional to solar radiation. PV cell can generate around 0.5 to 0.8 volts. During cloudy weather due to varying insolation levels the output of PV array varies. The MPPT is a process which tracks the maximum power from array and by increasing the duty cycle of the DC-DC boost converter, the output voltage of the system is increased. This paper presents the cuckoo mppt technique for PV system along with SMC controller methods in grid connected photovoltaic (PV) systems for optimizing the solar energy efficiency.

\section{INTRODUCTION}

At present, most of energy demand in the world relies on fossil fuels such as petroleum, coal, and natural gas that are being exhausted very fast. One of the major severe problems of global warming is one of these fuels combustion products, carbon dioxide; these are resulting in great danger for life on our planet [1].

Among all the available Renewable energy sources, PV array systems are trusted to play a significant role in prospective energy production. PV systems transform photon energy into electrical energy. These energy systems generate low voltage output, thus, high step-up dc/dc converters are employed in many applications, including fuel cells, wind power, and photovoltaic systems, which converts low voltage into high voltage. Due to the increasing demand on electricity, and limited availability and high prices of non-renewable sources, the photovoltaic (PV) energy conversion system has becomes an alternative as it is freely available, pollution free, and has less operation al and low maintenance cost. Therefore, the utilization of PV energy systems has to be increased for standalone and as well as grid-connected modes of PV systems. Photovoltaic $(\mathrm{PV})$ as a renewable energy resource naturally is not stable by location, time, season and weather and its installation cost is comparatively high. An important consideration in increasing the efficiency of PV systems is to operate the system near maximum power point (MPP) so to obtain the approximately maximum power of PV array. For getting maximum possible energy produced by a solar system.

Also maximum power point tracking (MPPT) techniques are used for improving the performance of PV systems, a high efficiency power converter which is designed to extract maximum power from a PV panel is usually considered. Generally, there 
will be a unique point on the V -I curve, called the Maximum Power Point (MPP), at which the whole PV system serves with maximum efficiency and produces its maximum power output. The position of the MPP is unknown, but can be placed either by search algorithms or through calculation models. Maximum Power Point Tracking Techniques (MPPT) are used to maintain the PV array's operating point at the precise position where maximum power can be delivered. Various MPPT algorithms have been considered in the literature; some of them are the Perturb and Observe ( $\mathrm{P} \& \mathrm{O})$ method, the Incremental Conductance (1C) method the Artificial Neural Network method, the Fuzzy Logic method. The P\&O and IC techniques, are the most widely used. In this paper, four MPPT algorithms are considered: $\mathrm{P} \& \mathrm{O}$, Incremental Conductance (1C) method, Fuzzy Logic method, Particle Swarm Optimization method. These methods are quite easily implemented and have been widely adopted for low cost applications. Other methods such as Sliding Mode, are not considered in this paper, because they are more complex and rarely used.

This paper focuses on developing a simulation model for grid connected PV system with Cuckoo MPPT technique to improve the performance of system. This simulation model is performed using Matlab and SimPower Systems and results are presented to verify the effectiveness of the proposed system. The proposed grid connected PV generation system is shown in figure 1 .

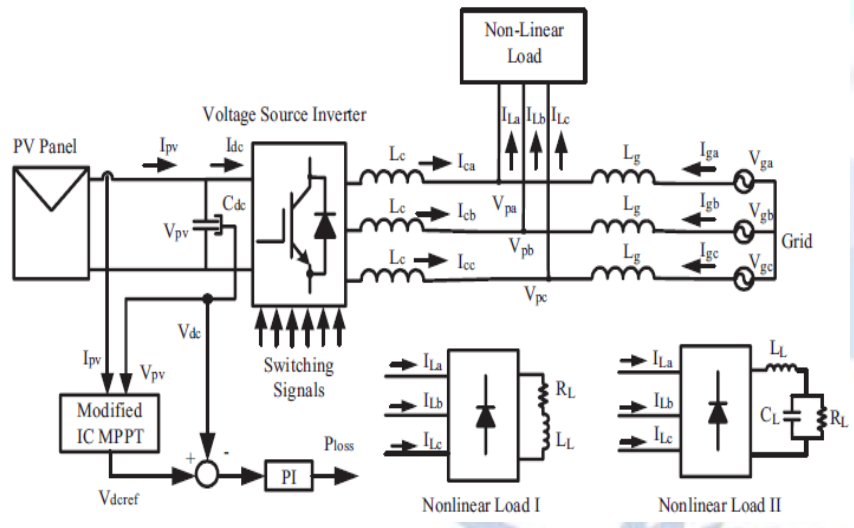

Figure 1: Diagram for Proposed System

\section{Photovoltaic ARray Modeling}

In the PV network of electrical phenomenon, cell is the necessary part. For the raise in appropriate current, high power and potential difference, the sunlight dependent cells and their region unit joined in non-current or parallel fashion called as PV exhibit are used. In practical applications, each and every cell is similar to diode with the intersection designed by the semiconductor material. When the light weight is absorbed by the electrical marvel sway at the point of intersection, it gives the streams at once. The (current-voltage) and (Power-Voltage) attributes at absolutely unpredictable star intensities of the PV exhibit are represented in figure 3 , whereas the often seen existence of most electrical outlet on each yield is shown in power diagram 2 .

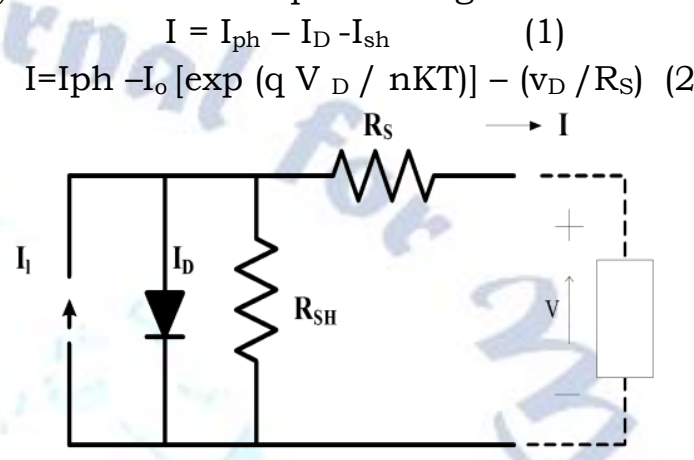

Figure 2: PV Electrical Equivalent circuit

Solar cell output power is given as the product of $\mathrm{V}$ and I

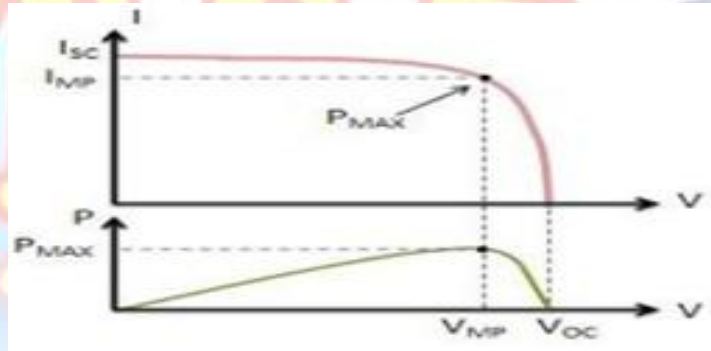

Figure 3: Response of output characteristics of PV Array

\section{Control Technique for VSI}

Figure 4 shows the structure of the proposed ASMC employed with the instantaneous power theory for the GCPVS. The reference active power and reactive power for VSI are calculated using the instantaneous power theory. Then the reference inverter current is calculated using the following equations. After implementation of ASMC, the required gate signal is generated using equation, which is applied to the VSI.

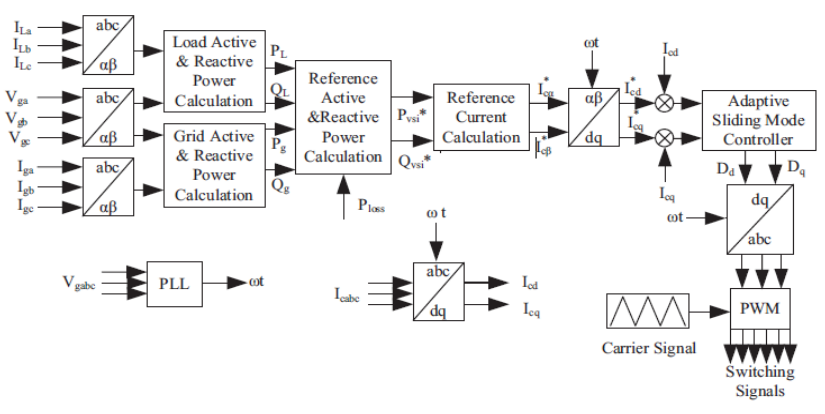


Figure 4: Control Diagram for VSI

$$
\begin{gathered}
{\left[\begin{array}{c}
I_{c \alpha}^{*} \\
\dot{I}_{c \beta}^{*}
\end{array}\right]=\left[\begin{array}{cc}
V_{\alpha} & V_{\beta} \\
-V_{\beta} & V_{\alpha}
\end{array}\right]^{-1}\left[\begin{array}{c}
P_{v s i}^{*} \\
Q_{v s i}^{*}
\end{array}\right]} \\
{\left[\begin{array}{c}
\dot{I}_{c d}^{*} \\
\dot{I}_{c q}^{*}
\end{array}\right]=\left[\begin{array}{c}
\cos \varphi \sin \varphi \\
-\sin \varphi \cos \varphi
\end{array}\right]\left[\begin{array}{c}
I_{c \alpha}^{*} \\
\dot{I}_{c \beta}^{*}
\end{array}\right]}
\end{gathered}
$$

It employed IPT and power balance to generate the reference current for VSI. The a, $\beta$ components of grid voltage, grid current and load current can be calculated using Clarke transformation as follows. The load active and reactive power is calculated using the equation as follows

$$
\left[\begin{array}{l}
P_{L} \\
Q_{L}
\end{array}\right]=\left[\begin{array}{cc}
V_{\alpha} & V_{\beta} \\
-V_{\beta} & V_{\alpha}
\end{array}\right]\left[\begin{array}{l}
I_{\alpha} \\
I_{\beta}
\end{array}\right] .
$$

The real power and reactive power of the load comprises of an average component and an oscillating component. The oscillating component of power can be obtained using a low pass filter $(\mathrm{LPF})$. The dc link capacitor voltage of VSI is measured at the time of operation of VSI. A PI-controller is employed to regulate the dc link voltage. The reference dc link voltage is obtained as the output of the modified IC MPPT algorithm. The output from the PI-controller represents as power loss $\left(P_{\text {loss }}\right)$ which flows to (from) the capacitor $C_{d c}$ to keep the dc link capacitor voltage at a fixed value.

$$
P_{g}=V_{g \alpha} I_{g \alpha}+V_{g \beta} I_{g \beta}
$$

If the (Ploss) is supplied by the PV panel, then the reference real and reactive power for inverter is calculated as follows

$$
P_{v s i}^{*}=P_{L}-\bar{P}_{g}+\bar{P}_{\text {loss }}
$$

Accordingly the reference $\mathrm{d}-\mathrm{q}$ component of inverter current can be estimated by following equations

$$
\begin{gathered}
{\left[\begin{array}{c}
I_{c \alpha}^{*} \\
I_{c \beta}^{*}
\end{array}\right]=\left[\begin{array}{cc}
V_{\alpha} & V_{\beta} \\
-V_{\beta} & V_{\alpha}
\end{array}\right]^{-1}\left[\begin{array}{c}
P_{v s i}^{*} \\
Q_{v s i}^{*}
\end{array}\right]} \\
{\left[\begin{array}{c}
I_{c d}^{*} \\
I_{c q}^{*}
\end{array}\right]=\left[\begin{array}{r}
\cos \varphi \sin \varphi \\
-\sin \varphi \cos \varphi
\end{array}\right]\left[\begin{array}{c}
I_{c \alpha}^{*} \\
I_{c \beta}^{*}
\end{array}\right]}
\end{gathered}
$$

\section{CUCKOO MPPT ALGORITHM}

Due to its sound and aggressive reproduction strategies cuckoos are fascinating birds. Generally, cuckoo birds lay their eggs in communal nests and may remove others eggs to increasing hatching probability of their own eggs. Female cuckoos search and select a group of host spices with similar nest sites and egg characteristics to their own, then choosing the best from these nests.

Cuckoo birds start in looking for the best nest, and this is important step has an important role in cuckoo's reproduction method. To search for best nest and process of food, the Le'vy flight plays a key role. This type of behaviour is used in making optimization for different problems. The step length or Le'vy flight distribution is shown in equation.

$S=\alpha_{q}\left(V_{b t}-v_{j}\right) \oplus l e(\lambda)$

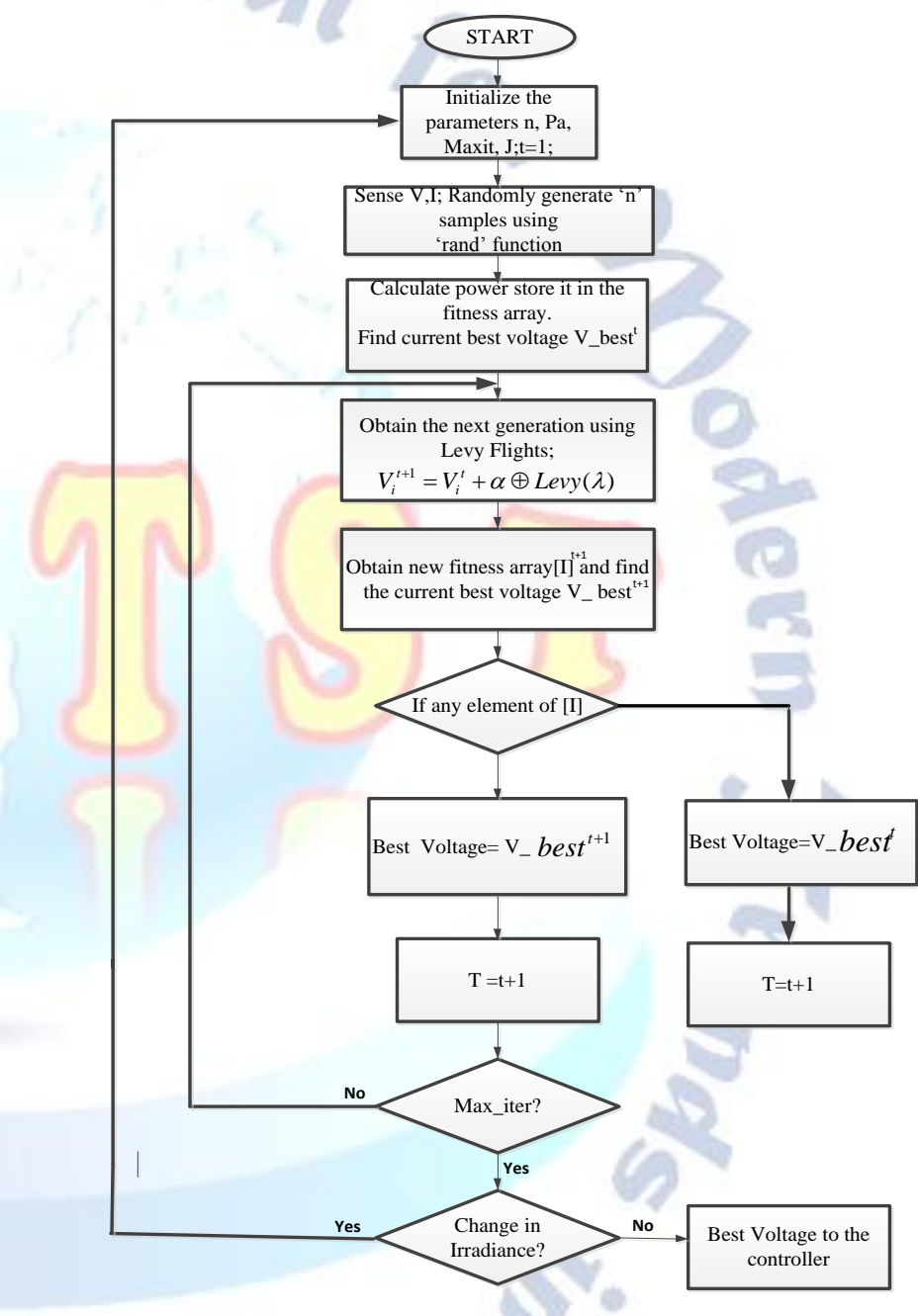

Figure 5: Cuckoo Search Algorithm

Figure 5, shows the flowchart for Le'vy based cuckoo search algorithm. In this the random initial solution of the operating voltage and current of PV panel is selected. The fittness of power is calculated as shown $\mathrm{P}=\mathrm{V}^{*} \mathrm{I}$.

Then find the best current, choose a random nest and generate a new solution by random walks as shown in equation.

$$
V_{i}^{t+1}=V_{i}^{t}+\alpha \oplus \operatorname{lev} y(\lambda)
$$




\section{SIMULATION STUDY}

The simulation is performed for GCPVS using both non-linear load I and II with ASMC-IC-IPT scheme shown in Figure 1 in MATLAB/SIMULINK. The performance of ASMC-IC-IPT scheme is compared with that of the SMC-IC-IPT scheme. The parameters used for the PV system are given in table-1.

\section{Case 1: With P\&O MPPT Technique}

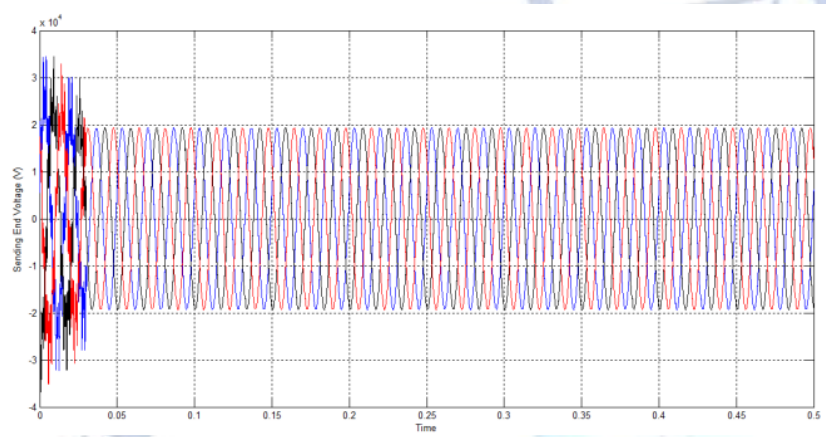

Figure 6: Simulation Result for Three Phase Output Voltage from Sending End

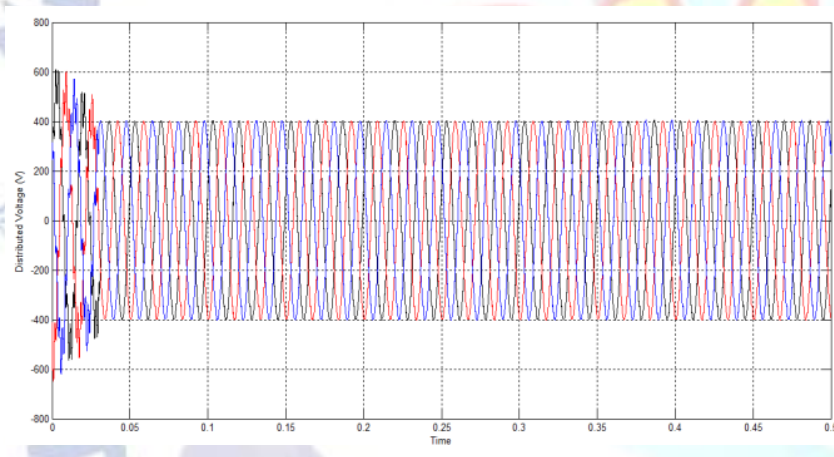

Figure 7: Simulation Result for Three Phase Output Voltage at Distribution Level

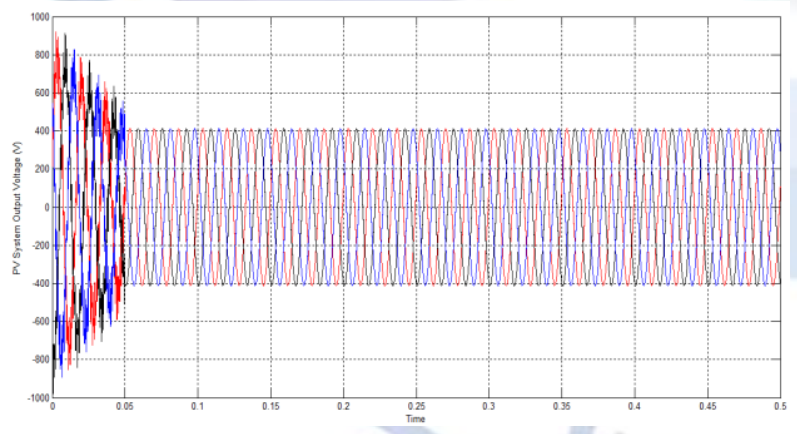

Figure 8: Simulation Result for Three Phase Output Voltage from PV System

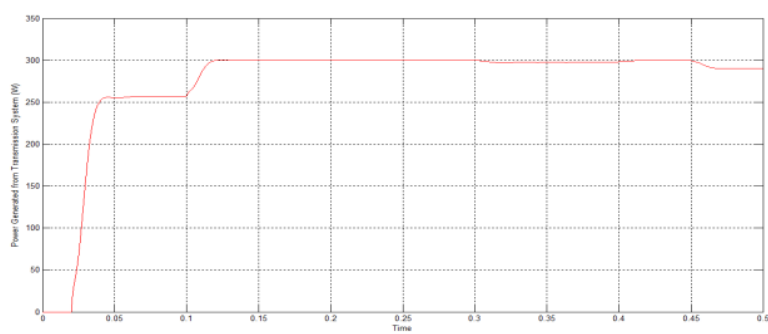

Figure 9: Simulation Result for Power Generated from the Transmission System

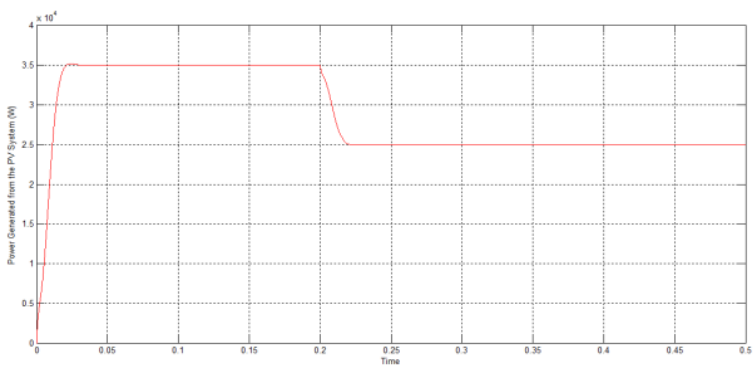

Figure 10: Simulation Result for Power Generated from the PV System

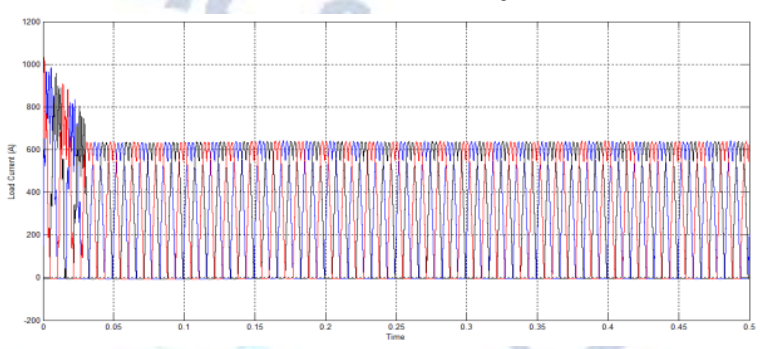

Figure 11: Simulation Result for Load current

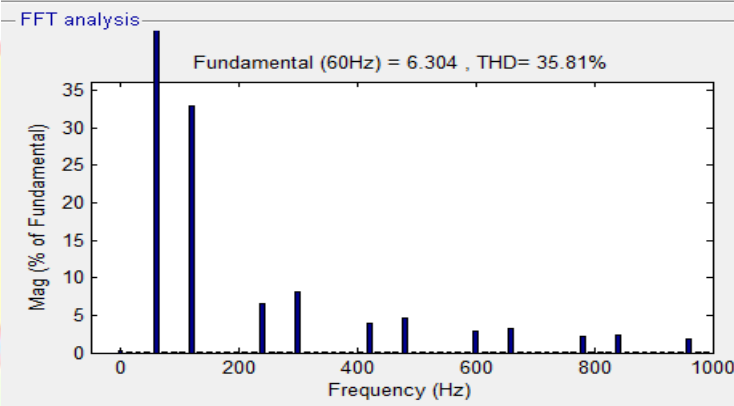

Figure 11: Harmonic Distortion for Source Current

\section{Case 2: With Cuckoo MPPT Technique}

Here, the proposed Grid Connected PV system is implemented with Cuckoo Search algorithm. In order to improve the performance of PV system a DC-DC converter is implemented. A Cuckoo-MPPT controller is implemented to generate gate signal for DC-DC Converter. The simulation results for PV system with Cuckoo MPPT technique is shown in figures.

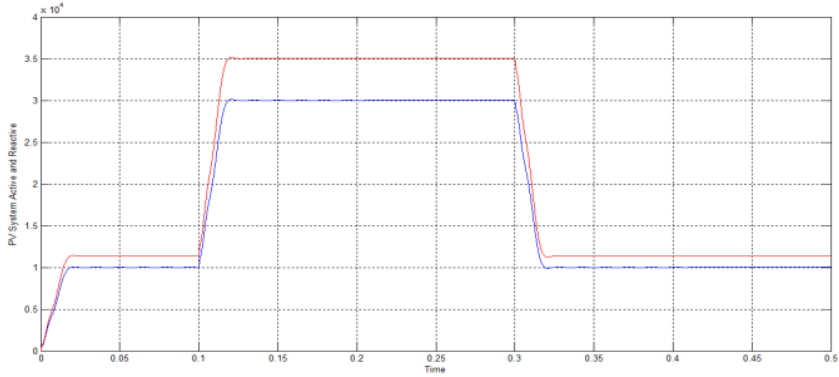

Figure 12: Simulation result for PV Power 


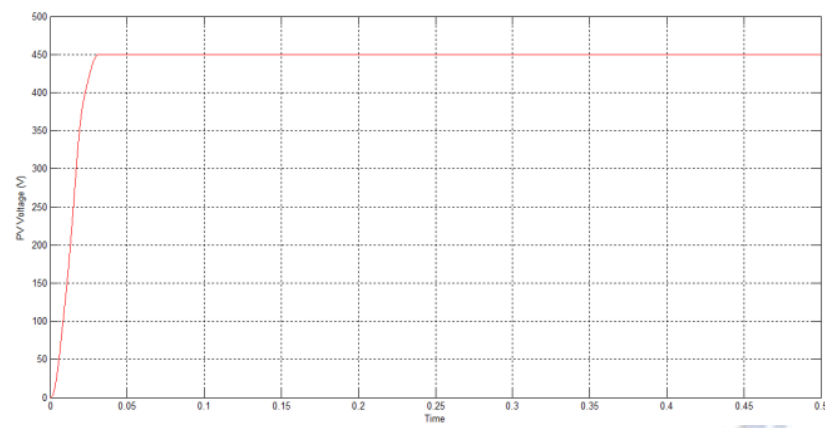

Figure 13: Simulation result for PV Voltage

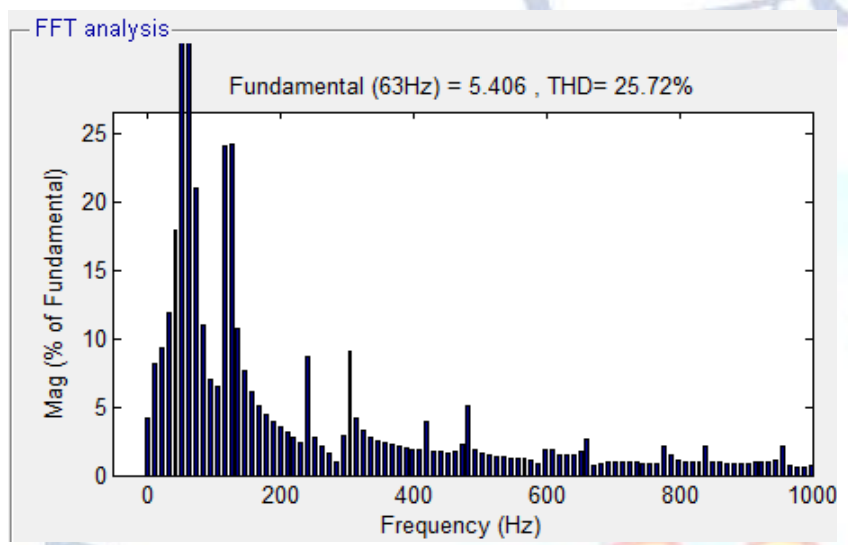

Figure 14: Harmonic Distortion for Source

\section{Current}

\section{CONCLUSION}

The paper presents a novel concept of integration of Cuckoo based PV system with grid interfaced hybrid system to improve the performance. The paper also presents effects of power quality on consumer and power utility systems. The converter proposed for PV system, reduces the distortions in currents, improved the power factor thus reducing the reducing the reactive power demand from the wind generator and the load at point of common coupling. Thus, the integration of PV and Grid devices maintains the desired power quality requirements. The Implementation of Cuckoo and PV control strategies are simulated in MATLAB/SIMULINK.

\section{REFERENCES}

[1] A.Q.Huang, M Baran, S.Bhattacharya "STATCOM importance on the integration of a large wind farm into a weak loop power system," IEEE Trans. Energy Conv., vol. 23, no. 1, pp. 226-232, Mar. 2008.

[2] Hook, Y. Liu, presents a paper on "Mitigation of the wind generation integration related power quality problems by energy storage," at EPQU J., vol. XII, no. 2, in 2006.

[3] Wind Turbine Generating System-Part 21, International standard-IEC 61400-21, 2001.

[4] J.Manel, "Power electronic system for grid integration of renewable energy source: A survey," IEEE Trans. Ind. Electron., vol. 53, no. 4, pp. 1002-1014, 2006, Carrasco.
[5] S. Ezhilarasan, P. Palanivel, S. Sambath "Design and Development of Energy Management System for DG Source Allocation in a Micro Grid with Energy Storage System" Volume 8, Issue 13, July 2015.

[6] S.Heier, Grid Integration of Wind Energy Conversions. Hoboken, NJ: Wiley, 2007, pp. 256-259.

[7] J.J.Gutierrez, J.Ruiz, L.Leturiondo, and A.Lazkano, "Flicker measurement system for wind turbine certification," IEEE Trans. Instrum. Meas., vol. 58, no. 2, pp. 375-382, Feb. 2009.

[8] Indian Wind Grid Code Draft report on, Jul. 2009, pp. 15-18, C-NET. 